OPEN ACCESS

Edited by:

Chandrashekhar Bhuiyan, Sikkim Manipal University, India

Reviewed by:

Patrick Thomson, University of Oxford, United Kingdom

Seifu Kebede Gurmessa, University of KwaZulu-Natal,

South Africa

*Correspondence: Kharis Erasta Reza Pramana k.e.r.pramana@tudelft.n

Specialty section

This article was submitted to Water and Human Systems, a section of the journal

Frontiers in Water

Received: 09 November 2021

Accepted: 31 January 2022

Published: 28 February 2022

Citation:

Pramana KER and Ertsen MW (2022)

Outward Appearance or Inward

Significance? On Experts'

Perspectives When Studying and

Solving Water Scarcity.

Front. Water 4:811862.

doi: 10.3389/frwa.2022.811862

\section{Outward Appearance or Inward Significance? On Experts' Perspectives When Studying and Solving Water Scarcity}

\author{
Kharis Erasta Reza Pramana* and Maurits Willem Ertsen \\ Department of Water Resources, Delft University of Technology, Delft, Netherlands
}

In the first decade of the 21st century, a water harvesting approach based on contour trenches - ditches to catch runoff-from Kenya was proposed as groundwater recharge technology in a semi-arid area in Ninh Phuoc district, Vietnam. In order to modify this solutions to tackle water scarcity, hydrological conditions at the site needed to be known. For such small-scale interventions, finding the most suitable set of (cheap and quick) efforts to study local hydrology is not easy. After our own study, we explored how different experts evaluated the chosen approach. The results from this evaluation suggest that different perspective for appropriate hydrological research can be found within a group of experts. This finding - in line with anthropologically inspired science studies - suggests that integrating different perspectives from stakeholders when working on suitable solutions in real-life water scarcity situations needs to be complemented with attention for different perspectives on the underlying hydrological processes and how they are to be studied. We discuss how this notion on the multiple perspectives intrinsic to hydrological research can be fruitfully included when developing water interventions.

Keywords: perspective, water scarcity, contour trenches, water quality, hydrological research

\section{INTRODUCTION}

The river Rhine saw its water quality problems increase dramatically in the late 19th century, caused by industrialization and subsequent dumping of wastewater in the Rhine and its tributaries. In the early 1930s, due to high concentrations of phenol and potential high salinity levels, Dutch drinking water companies established contacts with upstream riparian states (Disco, 2007). In July 1950, Germany, France, Luxemburg, the Netherlands and Switzerland founded the International Commission for the Protection of the Rhine. Next to recommend water protection measures, an international monitoring network was also a key activity. Soon, it proved to be necessary to improve the comparability of analysis results, as measurement and analysis methods differed in the participating countries. Apparently, the French and German monitoring campaigns, although taking samples from the same location (albeit from different banks), found different values of the same chemical components in the Rhine water. In other words, the German measurements produced another (perspective on) Rhine water quality compared to the French efforts. Once this was recognized, a common basis for shared assessment of the water quality in the Rhine became an important topic for further exchange of measurement techniques and data. 
We decided to start with a river-the Rhine-that may not be a river associated with water scarcity, even though it is expected to become an issue in this basin as well more often in the future, for two reasons. The first reason is what matters when considering water scarcity. The notion that water scarcity refers to inadequate availability of water is more often than not associated with water quantity. This in itself is not strange, as indeed the amount of water being available is a key determining factor for many socioeconomic activities. Our main case study in this paper does also engage with an intervention to increase the amount of water available in a relatively dry area of Vietnam. However, water availability is also seriously affected by issues related to water quality, as water resources might not be useable due to specific compounds in the water (see Zeng et al., 2013; Van Vliet et al., 2017). Sivapalan and Blöschl (2015) show an example how river water quality is much more valued than before. Especially in more urbanized areas, it can be observed that water quantity and water quality issues go hand in hand-with both water quality and quantity becoming serious issues in drier seasons and years as well, as is also clear in the Rhine basin. Apart from allowing us to start a paper on water availability with an example of river water quality, this expansion of water quality as an aspect of water scarcity would also mean that what we argue in this paper can be expanded to many other situations. We provide one additional example related to water quality and scarcity toward the end of this paper, as this example allows us to build upon our main argument.

This main argument is the second reason why we started with the Rhine narrative-it does offer a very useful example of the argument we aim to develop in this paper. Our main suggestion in this paper is that co-design of water-related interventions and research by different stakeholders from academia and society builds on negotiations on what counts as realistic perspectives of both interventions and hydrology. This means, as we continue building our main argument, that such negotiations create more than the intervention: interventions create the hydrological research itself - and thus principally the science of hydrologyas well. As such, we argue that stakeholder involvement-the seeking of partnerships in the process of (studying) hydrological change in interventions-affects knowledge, attitudes and behavior of all participants in a project's network. Hydrological scientists learn as much as the stakeholders about hydrology. Such an image is an important correction of the standard image that water-related interventions are based on fixed (hydrological and water resources) knowledge systems that researchers simply need to communicate to the other stakeholders (Ertsen, 2002; see Poolman, 2011 for more discussion on stakeholder participation in small-scale water initiatives).

Next to developing this argument in detail, using one case study, we propose ways to incorporate our more theoretical notions to practices in which interventions and hydrologyor policy and science in general terms-are linked. This paper discusses in detail one setting in Vietnam to show how different perspectives on hydrological aspects of contour trenching (could) have had immediate impact on the hydrological field work itself. In our own field and model study, we made specific choices - with good reasons, but leading to a certain perspective of the local hydrology. Afterwards, as explained in Pramana and Ertsen (2016), our experts came up with different suggestions for field and model studies-and thus potentially other hydrologies of the same setting. As such, we provide an example of interdisciplinary water research dealing with the structure of and consequences for hydrological knowledge claims. After positioning our argument further, we expand on the hydrological study at stake, to discuss how our own work was influenced and created by our own knowledge claims and by interventions from others. Then, we will specify the knowledge claims from other experts can be understood, which is followed by a more conceptual discussion on knowledge-related perspectives. The general recommendations that result from this discussion are translated in one example-based on our current joint research effort.

\section{POSITIONING THIS PAPER}

Whether discussing water quantity or quality, it is clear that a more complete understanding of such issues requires building relations between different academic disciplines, and between academic and other practices. Given that humans change landscapes through interventions for many purposes due to human demands (Ehret et al., 2014), for example interventions to deal with water scarcity in agriculture (Pachpute et al., 2009) or sand dams for subsurface storage (Lasage et al., 2008), human agency is continuously changing present and future water systems and hydrological processes, which means we need to build deeper understanding of human-water dynamics (Ertsen et al., 2014; Sivapalan et al., 2014). Within this emerging interdisciplinary field (now usually labeled as socio-hydrology), our earlier work suggested a systematic approach how to include explicit recognition of human actions in the development of water interventions and its associated hydrological research, in the planning of such research (Pramana and Ertsen, 2016). Based on our field studies, we suggested the usefulness of considering a range of possible actions by human agents related to the intervention (like moving a monitoring station that is seen as a nuisance) and their effect on hydrological research (like lower amounts of data) - which we labeled as unexpected surprises and possible actions. We proposed a cost-benefit analysis in terms of gains of knowledge vs. costs of research, to plan hydrological field work that includes possible surprises in the process of doing this field work.

Any intervention can be understood in terms of cooperation and negotiation between actors, which together create a process of (re)shaping design, implementation and use of that intervention (Ertsen and Hut, 2009). In other words, water planning and management are typically co-organized or "coengineered" by several actors of different types (Daniell et al., 2010). The relevance to look at the interactions between humans (as initiator and/or stakeholder of intervention and/or research itself) and the hydrological system has been recognized more and more within the hydrological community. Apart from the academic interests in socio-hydrology, the recent contribution by Rangecroft et al. (2021) suggests that interdisciplinary water 
research should be conducted during fieldwork and provides several examples of good practices. These examples offer insights on why stakeholders make choices, and how building connections between different stakeholders and specialist can be arranged-including suggestions how (knowledge and methods of) social scientists can be incorporated by hydrologists in waterrelated studies (see also Law and Mol, 2008).

Indeed, in order to design more successful interventions, building on a wider knowledge base beyond hydrology, makes sense. Having said that and using one of our three case studies from Pramana and Ertsen (2016), in this paper we expand on both Rangecroft et al. (2021) and on our own original argument. We mobilize the social sciences (and humanities for that matter) in an additional way to clarify an important observation that we already discussed in Pramana and Ertsen (2016). When asked what would be the more suitable measurement techniques to be applied to study certain hydrological processes, our hydrological experts did not fully agree with each other. Without suggesting that this is a strange finding-or even a problem-such different claims on what and how to measure, when used to design a field campaign, could very well result in different data sets from the same setting. Different data create different settings-and as such hydrological reality. We do not aim to make our reasoning more theoretical than necessary-as we want to suggest practical approaches to deal with diversities of opinions in hydrological studies-but it is worth noting that different data would indeed create different versions of that setting, as they did in the Rhine. One researcher would tell another story about a situation than another researcher from the same discipline might tell.

This reasoning is in line with well-known anthropological work on scientific studies like Latour (1987) who shows that the notion of an objective external reality solving issues between scientists is problematic, as the daily activities of those scientists show how they create that same external reality. In Mol (2002), we discover how the different practices within the same hospital create their own version of "the disease" arteriosclerosis. Mol concludes that in the different daily practices in the hospital, different diseases are being created and used to guide those practices. Both Latour and Mol do not suggest at all that these different perspectives of what is typically seen as one "real" setting is a problem. That different perspectives on what counts as "good" or "useful" knowledge can be (seen as) problematic, however, is illustrated by Junier (2017) who shows that the question whose version of specific causal relations is included in hydrological models goes beyond mere practical issues. All three studies we referred to are firmly based in the humanities, but it is important to note that they are as much based on extensive field work as many of the studies that build the field of hydrology. Our three studies simply argue that daily practices by researchers and academically trained practitioners are built on different interpretations of the issues of relevance for those practices. We have recognized this notion in our own work and would like to explore in this paper with the aim of providing suggestions to the discipline how to use this notion as productively as the ones already provided by other recent work on mobilizing insights from other fields in hydrological studies. For this, we move to Vietnam.

\section{CONTOUR TRENCHES IN VIETNAM}

In the study of Pramana and Ertsen (2016), the Vietnam case has been discussed in terms of the more detailed hydrological measurement and modeling approaches and results. Based on these, we discussed how scenarios on the hydrological research can be developed further for a better understanding of the hydrological impact of contour trenches. Even more details can be found in Pramana (2022). In this paper, we will present the actors and on how the project went in terms of the intervention and its associated hydrological research. Having a broader picture on the sequence of the process of intervention and research allows us to consider our options and thus choices we made. This intervention and research project was conducted by a Dutch consortium consisting of a consultancy company (Royal Haskoning/RH), two research institutions (UNESCO-IHE Delft/IHE and TU Delft), one non-governmental organization (Westerveld Conservation Trust/WCT), in close collaboration with a Vietnamese governmental agency, the Department of Natural Resources and Environment (DONRE) and the local community. WCT and RH were the initiator of the idea to apply contour trenches in the area. The local community participated in the decision-making of both intervention and research (Pramana and Ertsen, 2016).

\section{The Project}

The idea to use contour trenching to harvest runoff water and infiltrate it to feed groundwater in Vietnam originated from Amboseli, Kenya, where the approach was developed and implemented by WCT in 2002. In 2007, the same technique was introduced to a small Vietnamese community in Phuoc Nam, Ninh Phuoc district. Between January and August 2007, the contour trenching concept was presented to the local community. Photos, drawings, and slideshow presentations were used. Two main impacts were foreseen to result from the intervention: subsurface water storage and increased vegetation growth. These impacts were discussed between the initiators, governmental authority, and the local community. In line with the original Kenyan project, the proposed contour trenches were 4 meters wide and 1 meter deep, with almost vertical side walls (see Figure 1, left side). The distance between the trenches was set at about $36 \mathrm{~m}$. At the beginning, 97 hectares of potential area for contour trenching was identified. However, as detailed in Pramana and Ertsen (2016), at the end of the intervention period, due to limited landowner's will and permission, the trenched area was much less-namely 22 ha.

In October 2007, a first agreement between the local community and the initiators to implement contour trenches was reached. A monks' organization provided its land to be utilized, providing about 8 ha (Pilot Area 1). The area was uncultivated land, generally covered by small bushes, cactus and erosion gullies. Random cattle, owned by surrounding pastoralists walked freely in this area. As planned, this first stage of construction resulted in (seven) trenches with a width of $4 \mathrm{~m}$ (intervention A, see Figure 2) and different lengths being constructed along the contours. The trenches themselves were dug using an excavator. The excavated soil was placed downhill of the trenches; a 


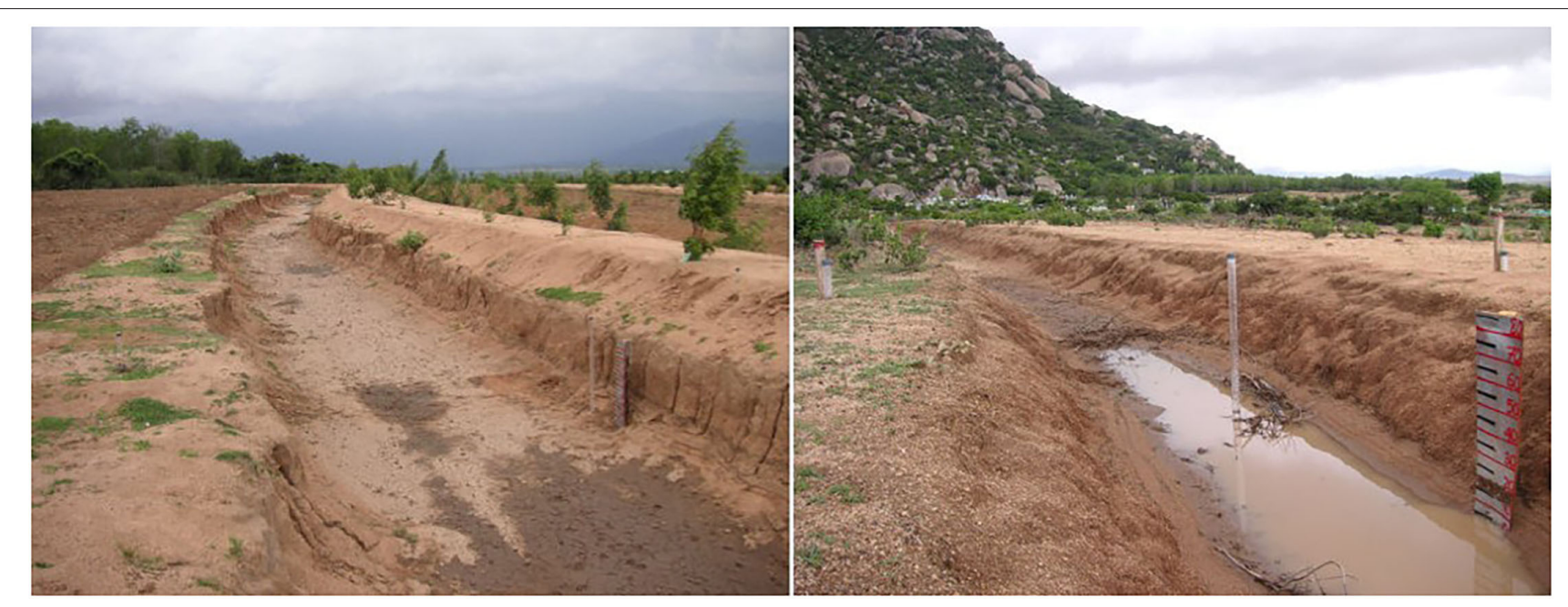

FIGURE 1 | The large (left) and small (right) dimension of trench.
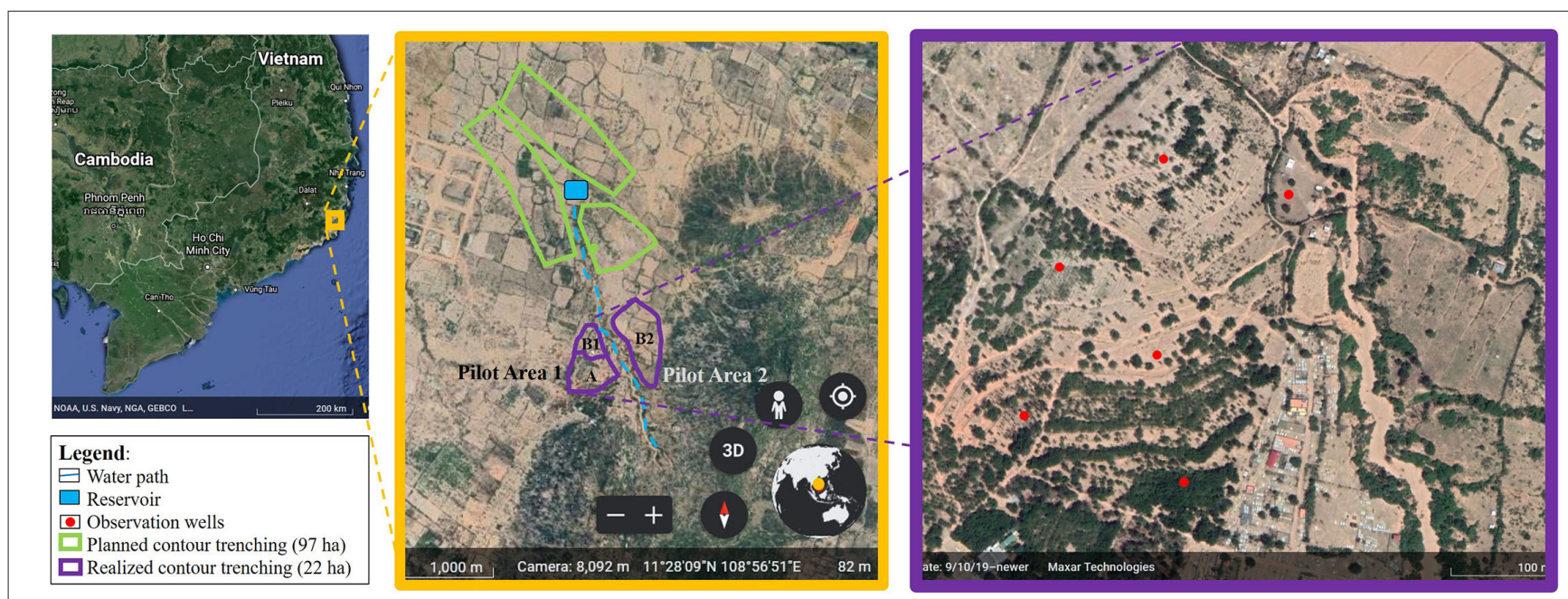

FIGURE 2 | The spatial development of contour trenches in Vietnam.

bulldozer evenly distributed and afterward compacted the soil deposits. About 5 ha of the total area were covered with this type of trenches, when in March 2008, the initiators and the monks' organization evaluated the contour trench design. Even though the trench dimension had been discussed several times before the construction, the monks' organization was unhappy with the trenches being rather wide and deep. A meeting to discuss this issue was set up. All parties in the consortium gathered for lunch at the monks' temple. It was clear that the monks did not like the trenched area: the trenches were too big. Perhaps surprising, safety (livestock could perhaps fall into the trench) was not an issue. Nevertheless, as a result, the monks refused to continue with any type of intervention on their remaining land. Hence, the construction plan of Pilot Area 1 had to be stopped.
In April 2008, RH approached other landowners with plans for smaller contour trenches, with the expectation that construction of trenches could be continued. The new trenches would have a bed width of $1 \mathrm{~m}$ with a top width of $2.5 \mathrm{~m}$ and side slopes of 1:1. The depth was $0.75 \mathrm{~m}$ [(intervention B1, see Figure 1 (right)]. The distance between the trenches was reduced to $25 \mathrm{~m}$. In May 2008, one of the farmers in the area agreed that the design would be more esthetic. He provided about 1 ha of his land (Pilot Area 2) for the smaller contour trenches. Hence, RH constructed five contour trenches, with different lengths along the contour. In August 2008, after the monks' organization saw the result of Pilot Area 2, the monks indicated interest in the smaller trenches being implemented on their remaining land as well. As a result, six smaller trenches were constructed at the remaining land of Pilot Area 1 (intervention B2). Progressively, 


\begin{tabular}{|c|c|c|c|c|c|c|c|c|c|c|c|c|c|c|c|c|}
\hline & \multicolumn{4}{|c|}{2007} & \multicolumn{4}{|c|}{2008} & \multicolumn{5}{|c|}{2009} & \multicolumn{3}{|c|}{2010} \\
\hline & $\mathrm{J}$ & & \begin{tabular}{l|l|l|l}
$A$ & $S$ & 0 & 1 \\
\end{tabular} & $\mathrm{ND}$ & 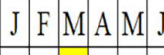 & & \begin{tabular}{|l|l}
$A$ & $S$ \\
\end{tabular} & $\begin{array}{lll} & \mathrm{N} & \mathrm{D} \\
\end{array}$ & & $\begin{array}{lllll}\mathrm{F} & \mathrm{M} & \mathrm{A} & \mathrm{M} & \mathrm{J} \\
\end{array}$ & & 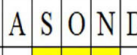 & D & $\mathrm{F} M \mathrm{M} A \mathrm{M}$ & & 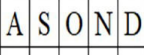 \\
\hline Field visit & & & & & & & & & & & & & & & & \\
\hline Rainfall measuren & & & & & & & & & & & & & & & & \\
\hline Soil moisture mea & & & & & & & & & & & & & & & & \\
\hline Water level meası & & & & & & & & & & & & & & & & \\
\hline Groundwater leve & & & & & & & & & & & & & & & & \\
\hline Isotope sampling & & & & & & & & & & & & & & & & \\
\hline Intervention plan & & & & & A & B & & & & B2 & & & & & & \\
\hline Negotiation & & & & & & & & & & & & & & & & \\
\hline
\end{tabular}

FIGURE 3 | Schematization of hydrological research, intervention and conditions for negotiation.

other landowners next to Pilot Area 2 requested the same trench design to be constructed on their land. In October 2008, the implementation of the big and small trenches yielded an area of 22 hectares in total.

\section{The Hydrological Research}

In October 2007, before the construction of the actual trenches had started, a setup for a field campaign was discussed and introduced-including rainfall, soil moisture, surface water, and groundwater level measurements. Two rain gauges were sited at two different locations, uphill and downhill from the planned intervention area. Six access tubes were placed inside the trench area, and two were placed outside the trench area. Surface water measurements, using a diver, started at the location of an existing reservoir, close to the planned intervention area, monitoring inflows into the reservoir. The groundwater level measurements were established by constructing three observation wells, uphill and downhill the planned intervention area, which used divers too. The setup of hydrological research and spatial development of contour trenching can be seen in Figures 2, 3. More detail is provided below.

During the measurement period, however, the installed measurement devices had to be modified and adjusted. Two automatic rain gauges that had been placed at the roofs of local residences were clogged due to accumulated fine sand blown by the strong wind during the dry season. Fine sand was trapped in the rain gauge funnel, blocking rainwater to enter the tipping bucket. Thus, during the second wet season, loss of data occurred. In addition, the data logger fail when downloading data. Soil measurement with access tubes seemed to attract the local people, possibly because of the appearance above the soil surface. In any case, the tubes were taken out from the soil at the measurement locations. The diver at the reservoir and two divers from the three observation wells disappeared as well. These divers (both at the reservoir and observation wells) had been placed in an open area and could easily be reached. In addition, there was no secure installation for the divers, for example by using a strong padlock or installing them at isolated or private areas owned by a farmer. Only one observation well was constructed in a local farmers' yard close to the trench area. After the loss of three divers, observation wells were equipped with stronger padlocks. Furthermore, observation wells without divers were measured using local materials, with an Am-meter connected to a long electric cable, attached to an iron stick at its end. When the iron stick touched the water table, it would transmit an obvious current signal. A monk conducted these manual measurements during almost 3 years.

Although during the drafting of the research plan, the risk in failing to obtain a signal from infiltrated water was recognized, the observation well screen was installed close to the bedrock, which made it difficult to find the isotope signal of recharge in all wells. Nevertheless, stable isotope samples were still collected and analyzed. Fortunately, one of the upstream groundwater samples did contain the signal of rainwater. Locations to measure groundwater levels were added too during the field period. Since the contour trenching shifted from its original location plan to locations where community members agreed their land to be trenched, the measurement locations needed to be adjusted too. Thus, four new observation wells were constructed to investigate the recharge impacts inside the trench area.

\section{Developing Relevant Small-Scale Hydrology}

To study the hydrological impact of contour trenching-or, in other words, to construct a useful local hydrology-we selected several devices and approaches.

- Our two rain gauges (Casella tipping bucket, resolution $0.2 \mathrm{~mm}$, Bedford, UK) had been suggested by our partner from IHE. As already mentioned earlier, after negotiation with the local people, one rain gauge was installed on the roof of a building at a temple located uphill about $150 \mathrm{~m}$ from the study area, the other one was installed on the roof of a farmhouse located about $2 \mathrm{~km}$ downstream from the study area. The experience of clogged automated rain gauges, made us add a 
manual rain gauge, which was set next to the first automated rain gauge.

- To examine the impact of contour trenching on soil moisture in the unsaturated zone, we used a Time Domain Reflectometry (TDR) probe with access tubes. With the help of a local person, we installed the access tubes at locations in and one outside the trench, as well as in areas with and without the trenches.

- The water level in the trench during water accumulation in the wet season was measured to estimate the flux of the recharge. We then applied the water level and soil moisture measurements as inputs and calibration parameters in the modeling. Furthermore, we investigated the influence of the water level in the trench to the fluctuation of the groundwater.

- The groundwater levels were measured with divers (Schlumberger Water Services), based on the recommendation of our partner from IHE. After the loss of two divers in two different observation wells, groundwater level measurements were done manually on a 3 to 4 -day basis. We asked and negotiated with a local person to assist us further with the measurements.

- Given the availability of a spectrometer at the Isotope Laboratory of TU Delft, we initiated and conducted isotope analysis as well. Water samples-rainwater, ponded water in the trench, and groundwater-were taken from the field and analyzed in Delft.

- In the modeling part, we used Hydrus (2D/3D) for two reasons. First, the focus was on a combination of infiltration in the unsaturated and recharge in the saturated zone. Measurements in the unsaturated zone were limited, and modeling was selected to see how surface and groundwater could be connected. Second, fine sediment was trapped in the trenches, especially the first uphill one. After several events, a few $\mathrm{cm}$ of clay accumulated. This layer was included in the model domain to see its effect on flow directions, as growing influence of sedimentation is to be expected over the years.

Pursuing our research with the above setting, measurements and interventions were (co-)shaped on a particular moment. Observing local community members and how they reacted, stimulated different thinking and actions in the project consortium. Meanwhile, being confronted with the actions and ideas of others required an understanding of the processes involved in the intervention-based research itself. We perceived or observed the situation concerning measurements of smallscale intervention and re-interpreted both the measurement devices and the location of the intervention. The measurements demanded an effort from us to produce ideas on the relevant hydrological reality due to the loss of measurement devices and shifting intervention. Measurements remained limited, but modeling required measured data. Our modeling had to be performed with data from the research period. In line with Beven (2018), who suggested that modeling a hydrological system should preferably use both hydrological and tracer response information, we combined Hydrus (2D/3D) with isotope tracer data. However, our result showed a non-agreement on water flow paths to the subsurface between our modeling and the groundwater level data we had. This may have been partially due to having the geological conditions of the study area only available in qualitative format (compare with "soft data"; compare with Epting et al., 2009).

\section{EXPERTS DEFINING RELEVANT SMALL-SCALE HYDROLOGY}

In relation with how experts would deal with the same Vietnam case, Pramana and Ertsen (2016) provided a step-by-step survey interviewing 10 experts to gain their perspectives. As a theoretical exercise (in the sense that the suggestions would not be applied), the survey asked for experts' judgments and grading of three scenarios. In the first scenario, experts valued the existing research results. This was followed by the second and third scenario (which we will refer to below as Scenario A and B), to receive the experts' opinions on proposed extensions of the hydrological research and related budgets. At the end, experts were also given the chance to suggest any other methods they would propose to gain better understanding. The initial objective was to study these expert opinions in terms of costs and benefits, given the limited budgets and the possible gains in understanding the intervention (Pramana and Ertsen, 2016). Our focus in this paper-based on the same results-is to discuss similarities or differences in perspectives on hydrological research within a community of experts. When our experts were requested to score the existing measurements (Table 1), they generally agreed that the measurements and results provided a basic understanding of the hydrological processes of the contour trenches. However, several remarks, comments, and ideas emerged when discussing the results of our hydrological research in terms of adding research activities in case additional budget would be available.

In Scenario A, we included the option to expand the measurements by constructing one new observation well. Additionally, the sampling period for stable isotope tracer was extended. The observation well should be constructed properly-placed in line with the existing wells and its screen should be along the pipe, from near soil surface to the bedrock. Using this idea, recharge could become more apparent where the signal of infiltrated rainwater could infiltrate into the pipe directly. Thus, the groundwater fluctuation and sampling could confirm the existing results. In relation to this scenario, an expert mentioned that the available groundwater data would already allow observing fluctuations in (or seasonality of) groundwater. Another expert, however, claimed the need to measure two more years. Moreover, one expert acknowledged that the advanced method using isotopes would certainly offer good results. On the other hand, two experts were sceptic about this, with one claiming the new measurements could not lead to new insights and the other one suggesting that the data to validate the groundwater model would not become available. Yet, (how) to decrease the uncertainty remained an open question. Even with uncertainty potentially decreased, however, the latter expert doubted the possible outcome anyway-suggesting it would still produce confusing results. 
TABLE 1 | The experts' opinions.

\begin{tabular}{|c|c|c|c|c|c|c|c|}
\hline \multirow[t]{2}{*}{ No } & \multirow[t]{2}{*}{ Title } & \multirow[t]{2}{*}{ Institution } & \multicolumn{2}{|r|}{ Scenario A } & \multicolumn{2}{|r|}{ Scenario B } & \multirow{2}{*}{$\begin{array}{c}\text { Other suggestions } \\
\text { Remarks }\end{array}$} \\
\hline & & & Grade & Remarks & Grade & Remarks & \\
\hline 1 & PhD & Utrecht University & 7 & $\begin{array}{l}\text { Seasonality is already } \\
\text { included }\end{array}$ & 7 & $\begin{array}{l}\text { Disadvantage: profiles } \\
\text { measured only one time }\end{array}$ & $\begin{array}{l}\text { Require } 10 \text { year groundwater level } \\
\text { data }\end{array}$ \\
\hline 2 & $\mathrm{MSc}$ & Delft University & 8 & $\begin{array}{l}\text { Measure for at least } 2 \\
\text { years }\end{array}$ & 8.5 & $\begin{array}{l}\text { Model only tests hypothesis. } \\
\text { Measurements already } \\
\text { answered the research } \\
\text { question }\end{array}$ & - \\
\hline 3 & MSc & Delft University & 7 & $\begin{array}{l}\text { Isotope is an advanced } \\
\text { method with good } \\
\text { result }\end{array}$ & 7 & $\begin{array}{l}\text { One time measurement } \\
\text { equals to nothing }\end{array}$ & $\begin{array}{l}\text { To study the unsaturated zone, to } \\
\text { measure rate of recharge using SM } \\
\text { sensors etc. }\end{array}$ \\
\hline 4 & $\mathrm{PhD}$ & Delft University & 8 & $\begin{array}{l}\text { Need validation and try } \\
\text { to get more confidence } \\
\text { or to decrease } \\
\text { uncertainty. But it could } \\
\text { even lead to confusing } \\
\text { results }\end{array}$ & 8 & Hard to interpret & $\begin{array}{l}\text { Depending on Ks and soil moisture. } \\
\text { Challenging (qualitative result): } \\
\text { infiltration test and surface water } \\
\text { measurements }\end{array}$ \\
\hline 5 & PhD & Delft University & 7 & Sceptic & 8 & - & - \\
\hline 6 & Prof & UNESCO-IHE & 7,5 & - & 8 & - & - \\
\hline 7 & PhD & UNESCO-IHE & 7,5 & - & 8 & $\begin{array}{l}\text { Increase resistivity of water } \\
\text { by injecting sodium chloride }\end{array}$ & $\begin{array}{l}\text { More artificial tracer, (yellow dye), } \\
\text { soil moisture measurement below } \\
\text { the trench (use cheap sensors like } \\
\text { Decagon). A need of timely scale } \\
\text { measurements or time laps } \\
\text { measurements }\end{array}$ \\
\hline 8 & $\mathrm{PhD}$ & Delft University & 8 & - & 8 & - & $\begin{array}{l}\text { Previous measurements were } \\
\text { already sufficient }\end{array}$ \\
\hline 9 & MSc & Eindhoven-Deltares & 7 & - & 8 & - & $\begin{array}{l}\text { It would be an advantage to have } \\
3-\mathrm{D}\end{array}$ \\
\hline 10 & PhD & Delft University & 7,5 & - & 8 & $\begin{array}{l}\text { Expensive (cost magnitude } \\
\text { about } 10,000-30,000 \text { Euro } \\
\text { for a } 5 \mathrm{~m} \text { interval) }\end{array}$ & $\begin{array}{l}\text { Geophysical approach for spatial } \\
\text { information. Soil type analysis, } \\
\text { ground radar method, and 1-2 } \\
\text { points tracer (pollution) }\end{array}$ \\
\hline
\end{tabular}

In Scenario B, we proposed options for more measurement applications and/or more advanced methods. Besides one new observation well and stable isotope samplings, three other wells were to be constructed at the area with the smaller trenches. A possible advanced measurement was introduced by performing an electrical resistance tomography (ERT) survey for subsurface imaging. Several cross sections of the subsurface should be obtained during both dry and wet periods. Together, these new wells combined with ERT data would allow building more pronounced hypotheses regarding the difference in groundwater behavior with and without the intervention structure. Again, experts provided their feedbacks on the measurement proposal. Three expert suspected ERT survey to be useless, since it would measure only one profile at a time, and would thus be hard to interpret. Another expert argued that the measurements had already answered the research question, and thus would not need any addition to allow better understanding of recharge in contour trenching. On the other hand, two experts supported the ERT approach-with one suggesting to inject sodium chloride for better results and one advising to check on the costs since small intervals could require more budget.
Based on the open questions to the experts after they had valued the pre-constructed scenarios, five experts concluded that they were satisfied with the existing and proposed scenarios, while the five others did suggest extra measurements. One expert actually indicated that understanding recharge in the area should build on at least 10 years of groundwater level data. Another expert proposed to study the unsaturated zone, using soil moisture sensors. The preference for the type of sensors was not discussed, but we speculate that this might vary in terms of technology between experts, given different experiences with and availability in the research organization of the respective expert. Another expert argued that putting more effort in the infiltration tests and surface water measurements was key. The specific type of test and devices to measure were (again) not put into detail and might vary as well. Comparable soil moisture measurements with cheap sensors, adding tracers and investigating the time lap measurements, were of importance to another expert. In addition, another colleague would choose 3-D modeling over measurements to better understand the infiltration mechanism. Last but not least, an expert would approach the problem from a geophysical point of view, combining soil type analysis, ground radar and tracers. Our sample is too small for any relevant 
statistics, but the backgrounds and preferences of the experts concerning the type of selected measurements appear to be related-at least, they do not appear as random combinations.

\section{REALITY IN HYDROLOGICAL RESEARCH: WHOSE KNOWLEDGE COUNTS?}

In our Vietnam work, decision after decision resulted in the specific hydrological-research-and-intervention complexity that we mentioned. Choosing a model that fitted with the collected data appeared as possible-and we will certainly continue to defend our choices-but it still represents a possible realization of the relevant perspective of hydrological setting. Another hydrological researcher would or could particularly see a different approach to measuring and modeling of the same case. The result of the hydrological research presented in this study was not perfect, and could indeed have been conducted differentlyas our experts suggest. Follow-up actions on the measurement devices and modeling could probably add understanding, but on what would be preferable, our hydrological researchers showed disagreement.

The possibility of the existence of multiple perspectives on what is proper hydrology might sound like the narrative of the men that see different parts of the elephant, without realizing that they touched a complete elephant. This is already a strong metaphor for the existence of different ideas, but we think that our study brings it one step further. After all, the metaphor assumes that one already knows that what the men examine is indeed an elephant. What happens when we do not know that the observed is an elephant? In other words, once hydrological researchers do not agree exactly on what matters to understand a specific hydrology-once one cannot be certain about what is observed-one needs to come up with a convincing analysis on what is happening, has happened or may happenin hydrology or other fields. This does not mean that all options for hydrological research are automatically equally valid, or that all participants bring equal knowledge to the negotiations, but it clearly poses the question whose hydrological reality is emphasized-whose knowledge counts.

In a recent comment, Ertsen (2018) explores issues of uncertainty in situations where hydrology and humans interact. He identifies the challenges of using a definition of uncertainty based on a given external reality, that only needs identifying and uncovering. After all, different perspectives of risk and uncertainty should be expected-similar to different ideas on hydrological studies and interventions. Furthermore, he poses the question who decides what the relevant uncertainties are. In line with Latour (2013; see also De Vries, 2016; Junier, 2017), he argues that expertise is relative to other actors. Who is a "scientist" or a "stakeholder" is not automatically given, and as such the power to define relevance needs to be considered. In line with this reasoning, when discussing the intervention and associated research for the Vietnam case in paragraph 3, we find that hydrological research itself is subject to negotiation. However, in paragraph 4, we have shown that hydrological research itself is subject of negotiation. Negotiating the meaning of hydrological (reconstructions of) reality touches on "the negotiations between humans and non-humans that co-shaped the hydrology we aim to clarify, but also the negotiations on how we as scholars in the present chose to study that same hydrology and its associated uncertainties" (Ertsen, 2018).

Defining what we know less, or know differently, would quite often not only pose constraints on our certainties, but also allow additional insights in what we wanted to understand in the first place. Confronting different approaches and ideas on what is discussed-either between hydrological researchers, as discussed by Pramana and Ertsen (2016), between government and stakeholders, as discussed by Poolman (2011) or both, as discussed by Junier (2017) — typically should help clarifying where the shared understanding actually would be, what different ideas would be and how these matter.

\section{Relevance of Recognizing Perspectives on/of Hydrological Realities}

Returning to the main focus of the special issue, most scholars will relate water scarcity to factors beyond the hydrologicalindeed, the concept of anthropogenic drought (Van Loon, 2013) is widely accepted. Multiple perspectives are clearly recognized as well. Molden (2020) emphasizes the management aspects when dealing with water scarcity. Tzanakakis et al. (2020) emphasize the importance of water management revision. Vallino et al. (2020) provide an economic point of view in the agricultural sector. Cities do experience water scarcity, where pronounced water scarcity is due to water quality problems in Beijing (Zeng et al., 2013), which again is closely related to governance issues (Millington, 2018). Water scarcity constraints sectoral uses, also due to water quality (Van Vliet et al., 2017). What does our idea of the importance of perspectives on/within hydrology offer for such complex debates? Let us offer a brief insight on this relevance, using our current research efforts on water quality governance and monitoring in the Brantas River Basin in Indonesia.

The basin of the Brantas is about $11,800 \mathrm{~km}^{2}$. Compared to the Vietnam case, the larger study area involves more stakeholders. In our effort, six main stakeholders are involved: BBWS Brantas (the governmental agency for the river basin territory), the Provincial Environmental Agency (DLH), Perum Jasa Tirta I (PJT1, a semi-governmental company on water allocation, operation and maintenance), Ecoton (a local NGO), TAUW (Dutch consultancy), and TU Delft. This Brantas project builds on the need to simultaneously engage with the monitoring of the river water quality in the basin and the strengthening of water governance by (semi-)governmental institutions-including community participation. The academic interest focuses on the participatory planning of these two processes. The project uses notions as discussed by Junier and Mostert (2014), who provide an example of studying and understanding the development process and the perceptions of different stakeholders on the validity and usability of the Water Framework Directive Explorer. Furthermore, factors influencing collaboration in river basin management are clearly related to the (social) process of problem framing and decision making 
(Silveira et al., 2016). We are working on hydrological research, specifically engaging with citizen science setups in monitoring the water quality (similar to Thatoe Nwe Win et al., 2019).

In the Brantas, we observe both negotiations we noted above. In terms of different ideas on what is important to do, stakeholders represent both different ideas and different roles; as such, one can expect that the needs of different stakeholders, the beneficiaries of this joint effort, their opinions on the Brantas river will create different representation of that same Brantas. For example, Ecoton could see the river as being filled with too much industrial effluent, too much micro-plastic, and too many killed fish. PJT1 would see a need to regulate river water quantity, in order to distribute the water. BBWS would see the stream as a place to build or use water structures. In our project, we acknowledge that such multiple ideas on what counts as important exist-stakeholders have several agendas (e.g., Carr et al., 2012). These different positions already bring the question how a hydrological researcher should deal with these complexities in relation to his/her research to the front? Starting with the premise of different perspectives of stakeholders allows engaging with and planning for possible tensions in our own hydrological research-in line with what we ourselves suggested in Pramana and Ertsen (2016).

It is the second negotiation, however, that brings new possibilities develop the debate on river water quality in the Brantas basin. Bringing the different procedures of monitoring water quality in the Brantas into contact with each other allows developing a debate on how measurement data do (not) create different water qualities (instead of quality) in the Brantas. We are just beginning this process, but our first efforts (as reported in Willard, 2022) strongly suggest that the databases of the three measuring agencies (BBWS, DLH, and PJT1) do provide different perspectives on the same river in terms of river water quality and the most useful components to reconstruct this quality. We have not even started to include the measurements from Ecoton in the discussion, but it is clear that their point measurements-less structural as they may be-add the important element of sudden changes in quality (for example because of industrial discharges) to the mix. Recognizing that the measurements themselves allow building different claims on Brantas water quality will allow us to bring these different ideas together and discover possible consequences for and impacts to the hydrological research and water quality policy-similar to what we observed for the Rhine basin.

\section{EMBRACING HYDROLOGICAL PERSPECTIVES}

Recent studies, such as Di Baldassarre et al. (2018) and Rangecroft et al. (2021) call for different disciplines to collaborate and develop datasets and analytical tools capturing the longterm dynamics produced by the interactions of physical, social and technical processes. Interestingly ugh, the Editorial Nature Sustainability, vol. 4 (Editorial, 2021) claims that hydrological research has become less grounded, and suggests there is a need to push hydrology forward through unique conceptual advances and theoretical innovation. Whatever one thinks of such claimsas they might say more about the journal than the field-it is clear that the issue of water scarcity need to be studied in an interdisciplinary way. In the context of water scarcity, ongoing efforts for solutions are often arranged through interventions that combine with hydrological research. In connection with such research, a wide range of perspectives could be used: how does one measure in the field, how to translate those measurements into analysis and modeling, etcetera?

We have shared our ideas and method when investigating the hydrological impact of contour trenches in Vietnam, including possible changes if that research would have been done and continued by other experts. Similarly, we are currently involved in the implementation of interventions through research in a water quality monitoring campaign in the Brantas basin, Indonesia. Despite of the different scales, we recognize similar challenge when it comes to agreeing which intervention-based research is or should commonly be accepted in the hydrological community involved in the projects. In the Brantas, like in Vietnam, different types of intervention projects would differ in their associated research, and as such in the type of budget discussions one would expect. The local setting influences assumptions for the research approach, ranging from the choice of measurement devices to the preferences of the researcher him/herself. When a hydrological researcher comes from the project area/country, this could mean that he/she knows how to deal with the local conditions-and possibly that the research options can be better defined. On the other hand, differences in socio-economic position within countries (urban-rural, richpoor, young-old, etcetera) may be larger than a shared nationality

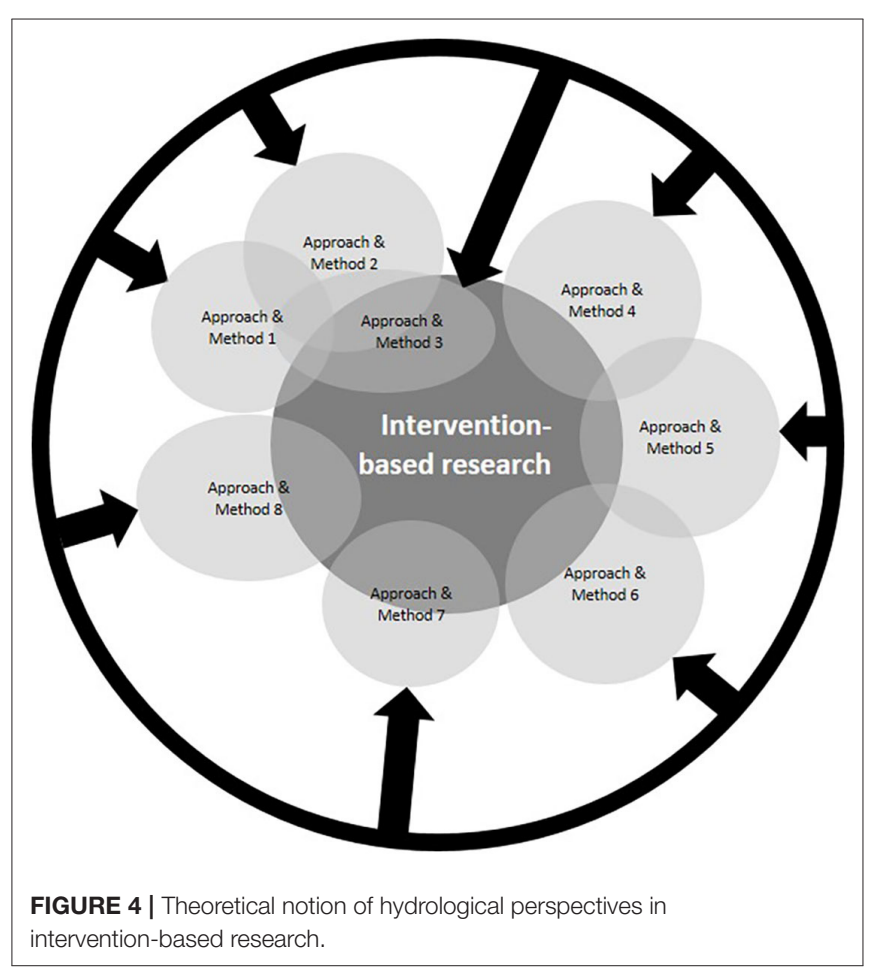


may suggest. Furthermore, data from different local institutions in the Brantas suggest that monitoring campaigns, interventions in river basins, and the hydrological research itself are closely linked. These different perspectives on local hydrologies offer new ways to engage with interdisciplinary water studies-both theoretical and practical.

As demonstrated, data produced from research or/and organization arrangement tend to be various and frequently determined by local conditions. Acknowledging that this is likely to produce different perspectives on local hydrology, we propose the notion of embracing those perspectives of different scholars. From one case study, we indicate multiple approaches and methods for the same case study, with larger or smaller overlap-indicating that we as researcher could think of different approaches and methods to conduct the research (light gray circles). These approaches and methods are related to perspectives, indicated as the outer black circle (see Figure 4).

This implies that in the hydrological science, both hydrological understanding of interventions and building hydrological science from these interventions are recognized. This paper nurtured the idea how to better think of hydrological research within a simultaneous intervention: we propose to conceptualize such an effort as building a perspective by a specific hydrological researcher. Using ideas and concepts from the humanities and social sciences, we claim that a hydrological researcher is required to think better in terms of deciding on measurements and models; what to measure or model, why certain types of measurements and models, where, and when, etcetera, as these choices shape the hydrological discipline

\section{REFERENCES}

Beven, K. J. (2018). On hypothesis testing in hydrology: why falsification of models is still a really good idea. Wiley Interdiscip. Rev. Water 5, e1278. doi: $10.1002 /$ wat 2.1278

Carr, G., Blöschl, G., and Loucks, D. P. (2012). Evaluating participation in water resource management: a review. Water Resources Res. 48, 11401. doi: 10.1029/2011WR011662

Daniell, K. A., White, I., Ferrand, N., Ribarova, I. S., Coad, P., Rougier, J. E., et al. (2010). Co-engineering participatory water management processes: theory and insights from Australian and Bulgarian interventions. Ecol. Soc. 15, 11. doi: 10.5751/ES-03567-150411

De Vries, G. (2016). Bruno Latour. Cambridge: Polity Press.

Di Baldassarre, G., Wanders, N., AghaKouchak, A., Kuil, L., Rangecroft, S., Veldkamp, T. I., et al. (2018). Water shortages worsened by reservoir effects. Nat. Sustain. 1, 617-622. doi: 10.1038/s41893-018-0159-0

Disco, C. (2007). Accepting father rhine? Technological fixes, vigilance, and transnational lobbies as' european'strategies of Dutch municipal water supplies 1900-1975. Environ. Hist. 13, 381-411. doi: 10.3197/096734007X243140

Editorial. (2021). Too much and not enough. Nat. Sustain. 4:659. doi: 10.1038/s41893-021-00766-8

Ehret, U., Gupta, H. V., Sivapalan, M., Weijs, S. V., Schymanski, S. J., Blöschl, G., et al. (2014). Advancing catchment hydrology to deal with predictions under change. Hydrol. Earth Syst. Sci. 18, 649-671. doi: 10.5194/hess-18649-2014

Epting, J., Romanov, D., Huggenberger, P., and Kaufmann, G. (2009). Integrating field and numerical modeling methods for applied urban karst hydrogeology. Hydrol. Earth Syst. Sci. 13, 1163-1184. doi: 10.5194/hess-13-1163-2009

Ertsen, M. (2002). "The technical and the social in engineering education," in Design and the Social Sciences, ed J. Frascara (London: CRC Press), 163-174. itself. Likewise, necessary questions to be considered include how hydrological researchers create their perspective. How do hydrological researchers argue about different perspectives? Hydrology is created in the process of obtaining data and further analysis performed by a hydrological researcher-within a larger community with members of different backgrounds and in different partnerships. Paying more attention to this continuous ambiguity to encourage a stronger co-evolutionary process of water-related intervention and associated research seems to be a reasonable requirement for the hydrological community.

\section{DATA AVAILABILITY STATEMENT}

The original contributions presented in the study are included in the article/supplementary materials, further inquiries can be directed to the corresponding author/s.

\section{AUTHOR CONTRIBUTIONS}

KP did the data collection for this article and drafted the main text. ME provided suggestions for the structure of the article and helped shaping the final text. All authors contributed to the article and approved the submitted version.

\section{FUNDING}

The Brantas project was funded by the Netherlands Enterprise Agency, under the program of Sustainable Water Fund (FDW), project number NL-KVK-27378529-FDW16046RI.

Ertsen, M., and Hut, R. (2009). Two waterfalls do not hear each other. Sand-storage dams, science and sustainable development in Kenya. Phys. Chem. Earth Parts ABC 34, 14-22. doi: 10.1016/j.pce.2008.03.009

Ertsen, M. W. (2018). Discussion of "perceptual models of uncertainty for socio-hydrological systems: a flood risk change example". Hydrol. Sci. J. 63, 1998-2000. doi: 10.1080/02626667.2018.1547504

Ertsen, M. W., Murphy, J. T., Purdue, L. E., and Zhu, T. (2014). A journey of a thousand miles begins with one small step-human agency, hydrological processes and time in socio-hydrology. Hydrol. Earth Syst. Sci. 18, 1369-1382. doi: 10.5194/hess-18-1369-2014

Junier, S. (2017). Modelling Expertise: Experts and Expertise in the Implementation of the Water Framework Directive in the Netherlands. ( $\mathrm{PhD}$ dissertation) Delft University of Technology.

Junier, S., and Mostert, E. (2014). A decision support system for the implementation of the water framework directive in the Netherlands: Process, validity and useful information. Environ. Sci. Policy 40, 49-56. doi: 10.1016/j.envsci.2014.04.004

Lasage, R., Aerts, J. C. J. H., Mutiso, G. C., and De Vries, A. (2008). Potential for community based adaptation to droughts: sand dams in Kitui, Kenya. Phys. Chem. Earth Parts ABC 33, 67-73. doi: 10.1016/j.pce.2007.04.009

Latour, B. (1987). Science in Action: How to Follow Scientists and Engineers Through Society. Cambridge, MA: Harvard University Press.

Latour, B. (2013). An Inquiry Into Modes of Existence. Cambridge, MA: Harvard University Press.

Law, J., and Mol, A. (2008). "The actor-enacted: Cumbrian sheep in 2001," in Material Agency, eds C. Knappett and L. Malafouris (Boston, MA: Springer), 57-77. doi: 10.1007/978-0-387-74711-8_4

Millington, N. (2018). Producing water scarcity in São Paulo, Brazil: the 2014-2015 water crisis and the binding politics of infrastructure. Polit. Geogr. 65, 26-34. doi: 10.1016/j.polgeo.2018.04.007 
Mol, A. (2002). The Body Multiple. Durham: Duke University Press.

Molden, D. (2020). Scarcity of water or scarcity of management? Int. J. Water Resources Dev. 36, 258-268. doi: 10.1080/07900627.2019.1676204

Pachpute, J. S., Tumbo, S. D., Sally, H., and Mul, M. L. (2009). Sustainability of rainwater harvesting systems in rural catchment of Sub-Saharan Africa. Water Resources Manage. 23, 2815-2839. doi: 10.1007/s11269-009-9411-8

Poolman, M. I. (2011). Present \& Future: Visualising Ideas of Water Infrastructure Design. (PhD dissertation) Delft University of Technology.

Pramana, K. E. R., and Ertsen, M. W. (2016). Towards systematic planning of small-scale hydrological intervention-based research. Hydrol. Earth Syst. Sci. 20, 4093-4115. doi: 10.5194/hess-20-4093-2016

Pramana, K. E. R., (2022). Small-scale Hydrological Intervention-Based Research: On Systematic Planning and Perspectives. (PhD dissertation) Delft University of Technology.

Rangecroft, S., Rohse, M., Banks, E. W., Day, R., Di Baldassarre, G., Frommen, T., et al. (2021). Guiding principles for hydrologists conducting interdisciplinary research and fieldwork with participants. Hydrol. Sci. J. 66, 214-225. doi: $10.1080 / 02626667.2020 .1852241$

Silveira, A., Junier, S., Hüesker, F., Qunfang, F., and Rondorf, A. (2016). Organizing cross-sectoral collaboration in river basin management: case studies from the Rhine and the Zhujiang (Pearl River) basins. Int. J. River Basin Manage. 14, 299-315. doi: 10.1080/15715124.2016.1170692

Sivapalan, M., and Blöschl, G. (2015). Time scale interactions and the coevolution of humans and water. Water Resources Res. 51, 6988-7022. doi: 10.1002/2015WR017896

Sivapalan, M., Konar, M., Srinivasan, V., Chhatre, A., Wutich, A., Scott, C. A., et al. (2014). Socio-hydrology: use-inspired water sustainability science for the Anthropocene. Earths Future 2, 225-230. doi: 10.1002/2013EF000164

Thatoe Nwe Win, T., Bogaard, T., and van de Giesen, N. (2019). A low-cost water quality monitoring system for the Ayeyarwady River in Myanmar using a participatory approach. Water 11, 1984. doi: 10.3390/w11101984

Tzanakakis, V. A., Paranychianakis, N. V., and Angelakis, A. N. (2020). Water supply and water scarcity. Water 12, 2347. doi: 10.3390/w12092347
Vallino, E., Ridolfi, L., and Laio, F. (2020). Measuring economic water scarcity in agriculture: a cross-country empirical investigation. Environ. Sci. Policy 114, 73-85. doi: 10.1016/j.envsci.2020.07.017

Van Loon, A. F. (2013). On the Propagation of Drought: How Climate and Catchment Characteristics Influence Hydrological Drought Development and Recovery. ( $\mathrm{PhD}$ dissertation) Wageningen University and Research.

Van Vliet, M. T., Flörke, M., and Wada, Y. (2017). Quality matters for water scarcity. Nat. Geosci. 10, 800-802. doi: 10.1038/ngeo 3047

Willard, T., (2022). Water Quality Measurements in the Brantas. (Master's thesis) Delft University of Technology.

Zeng, Z., Liu, J., and Savenije, H. H. (2013). A simple approach to assess water scarcity integrating water quantity and quality. Ecol. Indicat. 34, 441-449. doi: 10.1016/j.ecolind.2013.06.012

Conflict of Interest: The authors declare that the research was conducted in the absence of any commercial or financial relationships that could be construed as a potential conflict of interest.

Publisher's Note: All claims expressed in this article are solely those of the authors and do not necessarily represent those of their affiliated organizations, or those of the publisher, the editors and the reviewers. Any product that may be evaluated in this article, or claim that may be made by its manufacturer, is not guaranteed or endorsed by the publisher.

Copyright $\odot 2022$ Pramana and Ertsen. This is an open-access article distributed under the terms of the Creative Commons Attribution License (CC BY). The use, distribution or reproduction in other forums is permitted, provided the original author(s) and the copyright owner(s) are credited and that the original publication in this journal is cited, in accordance with accepted academic practice. No use, distribution or reproduction is permitted which does not comply with these terms. 